\title{
A Precious Fundus- Crystalline Retinopathy
}

\author{
Uma Radhakrishnan ${ }^{1}$ \\ ${ }^{1}$ Department of Ophthalmology, Sri Ramachandra Institute of Higher \\ Education and Research (SRIHER), Chennai, Tamilnadu, India.
}

\section{INTRODUCTION}

Bietti's dystrophy (AR) is characterized by deposition of crystals in the retina and superficial peripheral cornea. Crystalline corneoretinal dystrophy is an uncommon hereditary condition first reported by Bietti in 1937 as a corneoretinal degeneration. ${ }^{1}$ The hallmark of the disease was the crystalline characteristics of the retinal spots as well as those at the corneal limbus. ${ }^{2}$ The characteristic retinal crystals are observed in all cases, but the associated corneal dystrophy is not a consistent feature of the disease. ${ }^{3}$ Other reported features include progressive night blindness, constriction of visual field, subnormal ERG and EOG and defective colour vision in advanced

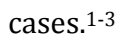

This condition is much more common in East Asians, particularly Chinese, than other ethnicities. ${ }^{4}$ We would like to present a case of Bietti's dystrophy discovered incidentally on routine fundus examination of a 36-year-old female who presented to our outpatient department with blurred vision and mild pain in both eyes.

\section{PRESENTATION OF CASE}

A 36-year-old female patient came with decreased vision for distance, mild eye pain in both eyes along with watering for three months. She was not diabetic. She was diagnosed with hypertension six months back, on treatment with tab Envas. There was history of occasional respiratory distress for past two years, on T. Deriphylline. There was no history of eye trauma or surgery. There was no history of any relevant metabolic disorder.

On examination, anterior segment findings were within normal limits in both eyes. Intraocular pressure was $17 \mathrm{mmHg}$ in right eye and $18 \mathrm{mmHg}$ in left eye. She underwent cycloplegic refraction followed by post-mydriatic test. Distance vision was correctable to 6/6p in right eye (with -0.5 DS/-0.5 DC x 20) and 6/9 (plano) in left eye; near vision was $\mathrm{N} 6$ in both eyes. Her colour vision was normal in right eye $(16 / 16)$ but abnormal in left eye $(3 / 16)$.

On dilated fundus exam, both eyes showed normal disc and vessels. Entire retina showed greyish discolouration with multiple small glistening whitish deposits in both eyes. In addition, left eye showed a pigmented scar close to macula. This remarkable fundus picture suggested possibilities for crystalline retinopathy.

Patient had difficulty in night vision. There was no history of similar complaints in any family member. Patient's corneas revealed no crystals on slit lamp evaluation. A provisional clinical diagnosis of 'Both eyes - Bietti's crystalline retinopathy with maculopathy in left eye' was made.

OCT macula revealed normal retinal thickness in both eyes. Perimetry attempted but test had to be aborted as patient was unable to visualise the light stimuli appearing on the visual field even on repeated attempts. Her electroretinogram report showed minimally reduced scotopic and photopic responses in both eyes.

Patient was counselled about eye problem, advised to continue spectacles and kept on follow up. On last follow-up, her vision had dropped marginally- unaided vision was 6/24 in right eye and 6/36 in left eye, improving to 6/18 and 6/24 with pinhole in right and left eyes respectively.
Corresponding Author: Dr. Uma Radhakrishnan, Department of Ophthalmology, Sri Ramachandra Institute of Higher Education and Research (SRIHER), Chennai, Tamilnadu, India. E-mail: ruma65512@gmail.com

DOI: $10.14260 /$ jemds/2020/266

Financial or Other Competing Interests: None.

How to Cite This Article: Radhakrishnan U. A Precious FundusCrystalline Retinopathy. J. Evolution Med. Dent. Sci. 2020;9(14):1227-1228, DOI: $10.14260 /$ jemds $/ 2020 / 266$

Submission 31-01-2020,

Peer Review 15-03-2020,

Acceptance 21-03-2020,

Published 06-04-2020.

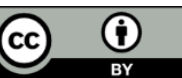



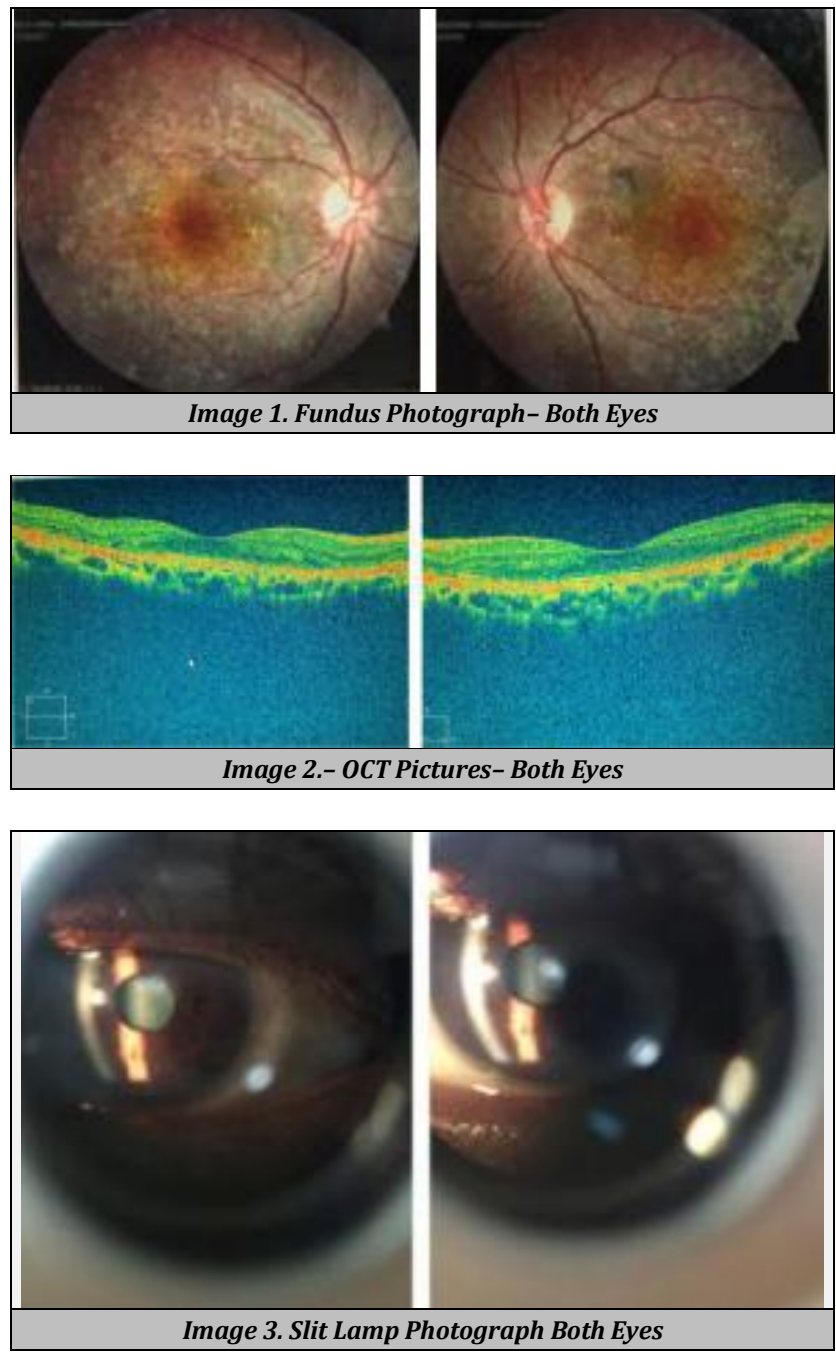

DIFFERENTIAL DIAGNOSIS

Bietti's retinopathy, calcified macular drusen, idiopathic parafoveal telangiectasias and long-standing retinal detachment.

\section{PATHOLOGICAL DISCUSSION}

This case is being highlighted as it is relatively rare. The mechanism of Bietti's crystalline corneoretinal dystrophy may be linked to an error in systemic lipid metabolism. Biopsy specimens from patients have demonstrated crystals resembling cholesterol or cholesterol ester and complex lipid inclusions in corneal and conjunctival fibroblasts. ${ }^{5}$ the rate of progression is variable- specific treatment not currently available. Young adults with slowly progressive visual impairment constitute the typical case.

\section{Signs According to Kanski's Clinical Ophthalmology}

- Superficial peripheral corneal crystals.

- Numerous fine yellow-white crystals scattered throughout posterior fundus, followed by localised atrophy of RPE and choriocapillaris at macula.

- Diffuse atrophy of choriocapillaris subsequently develops, with decrease in size and number of crystals.

- Gradual confluence and expansion of atrophic areas into periphery, leading to diffuse chorioretinal atrophy in end-stage disease.

\section{REFERENCES}

[1] Bagolini B, Loli-Spada G. Bietti's tapetoretinal degeneration with marginal corneal dystrophy. Am J Ophthalmol 1968;65(1):53-60.

[2] Welch RB. Bietti's tapetoretinal degeneration with marginal corneal dystrophy: Crystalline retinopathy. Trans Am Ophthalmol Soc 1977;75:164-79.

[3] Sahu DK, Rawoof AB. Bietti's crystalline dystrophy. Ind J Ophtholmol 2002;50(4):330-2.

[4] Kanski J, Bowling B. Kanski's Clinical Ophthalmology - a systematic approach. $8^{\text {th }}$ edn. Saunders Ltd., 2015: p. 65458.

[5] Wilson DJ, Weleber RG, Klein ML, et al. Bietti's crystalline dystrophy: a clinicopathologic correlative study. Arch Ophthalmol 1989;107(2):213-21. 